\title{
Models for multi-environment yield trials with fixed and random block effects and homogeneous and heterogeneous residual variances ${ }^{1}$
}

\author{
Fernando Casanoves ${ }^{2}$, Raúl Macchiavelli ${ }^{3}$ and Mónica Balzarini ${ }^{4}$
}

J. Agric. Univ. P.R. 91(3-4):117-131 (2007)

\begin{abstract}
Multi-Environment Trials (METs) are used to make recommendations about genotypes at many stages of plant breeding programs. Because of the genotype-environment interaction, METs are usually conducted in various environments (locations and/or years), using designs which involve several repetitions (plots) for each genotype at each environment. The stratification or blocking of plots within each environment enables one to consider part of the variability due to differences between plots. The objective of this study was to see how frequently the problem of heterogeneous variances across environments appears in Peanut Breeding Program METs, and to evaluate the effects of diverse spatial modeling strategies on the comparison of genotype means in each environment. A series of 18 METs in a peanut breeding program with randomized complete block design in each environment were simultaneously adjusted by using 1) classic analysis of variance models (fixed and random block effects); 2) mixed models adjusted with homogenous and heterogeneous residual variances to take into account that experiments conducted in different environments may vary in precision (residual variances). The results suggest that the analysis of variance models with a block design and heteroscedastic errors between locations are more appropriate than their homogeneous residual variance versions.
\end{abstract}

Key words: block design, heterogeneous variances, variety trials

\section{RESUMEN}

Modelos para ensayos varietales multiambientales con efectos de bloques fijos y aleatorios y varianzas residuales homogéneas y heterogéneas

Los ensayos multiambientales (EMA) se usan para recomendar genotipos en distintas etapas de los programas de mejoramiento. Debido a la presencia de interacción genotipo-ambiente, los EMA se conducen generalmente en diferentes ambientes (localidades y/o años) usando diseños que incluyen varias repeticiones (parcelas) de cada genotipo en cada

${ }^{1}$ Manuscript submitted to Editorial Board 27 September 2006.

${ }^{2}$ Centro Agronómico Tropical de Investigación y Enseñanza, 7170 Turrialba, Costa Rica.

${ }^{3}$ Department of Agronomy and Soils, University of Puerto Rico Mayagüez, PO Box 9030, Mayagüez, PR 00681-9030.

${ }^{4}$ Facultad de Ciencias Agropecuarias, Universidad Nacional de Córdoba, CC 509, (5000) Córdoba, Argentina. 
ambiente. La estratificación o bloqueo de parcelas en cada ambiente permite tener en cuenta la parte de la variabilidad que se debe a las diferencias entre las parcelas. El objetivo de este estudio fue estudiar cuán frecuente se presenta la heterogeneidad de varianzas residuales en el Programa de Mejoramiento de Maní-INTA, y evaluar los efectos de diferentes estrategias de modelamiento sobre la comparación de genotipos en cada ambiente. Se usó una serie de 18 EMA de un programa de fitomejoramiento de maní. Los EMA estaban arreglados de acuerdo a un diseño de bloques completos aleatorizados, y se ajustaron los siguientes modelos: 1) análisis de varianza clásicos (bloques fijos y aleatorios); 2) modelos mixtos ajustados con varianzas residuales homogéneas $y$ heterogéneas para tener en cuenta que los experimentos conducidos en ambientes diferentes podrían tener distinta precisión (varianza residual). Los resultados sugieren que los modelos de análisis de varianza con diseño en bloque y errores heteroscedásticos por localidad son más apropiados que los modelos con varianza residual homogénea.

Palabras clave: diseño en bloques, varianzas heterogéneas, ensayos varietales

\section{INTRODUCTION}

The estimation and comparison of genotype effects on multi-environment trials (METs) carried out at various locations require efficient mean yield (and other traits) estimations for each genotype. Commonly, METs are conducted under experimental designs with repetitions (various plots) for each genotype in each environment. The stratification or blocking of plots is a technique used to reduce the variation effects between experimental units. The blocks are groups of experimental units formed in such a way that the plots within the blocks are as homogeneous as possible. Designs with plot stratification such as the randomized complete block (RCB) design, incomplete block designs, and lattices are used in each environment in most METs. These designs are more efficient than the completely randomized design when the differences between experimental units in the same stratum are minimal and the differences between strata are maximal (Gusmao, 1986). Diversions from this condition may result in imprecise estimations for the genotype effects and/or overestimation of the error variance (Stroup et al., 1994). Generally METs include various genotypes, which explains why the block size necessary for repetitions in the trial is large, and it is difficult to assure homogeneity for the plots in the block. The nearest plots may be more similar than the distant ones, thus generating spatial variability. Spatial variability refers to the variation between observations in plots having spatial arrangements on the ground (Mercer and Hall, 1911). Variation from plot to plot within the same block may be due to competition between genotypes (Kempton and Lockwod, 1984), heterogeneity in soil fertility (Pearce, 1980), insect dispersion, weeds, crop disease or cultural aspects (Smith et al., 2001). Statistical procedures which consider the spatial variation between plots have been proposed. These procedures are varied and range from adjusting 
genotype means with observations in neighboring plots (Papadakis, 1937; Wilkinson et al., 1983; Besag and Kempton, 1986) to the use of models which include spatial correlations in random terms and which also adjust genotype means (Mead, 1971; Besag, 1974, 1977; Ripley, 1981). Stroup et al. (1994) compared methods and reached conclusions about the benefits associated with the modeling of spatial variation in wheat METs in the central region of the USA, using only one-location trials. For METs conducted in a location, Gleeson and Cullis (1987), Cullis et al. (1996) and Cullis and Gleeson (1991) conceptualize error variation as a whole, and they model it through its covariance structure, all of which obtains more precise estimations for the cultivar means than those derived from the plot stratification. Gilmour et al. (1997) partitioned the spatial variability between plots in a trial in local, global, and extraneous spatial variability. The local spatial variability refers to the differences between plots on a small scale, where intra-block variations are considered.

Modeling the spatial structure of the plots as distance functions can be done in the context of mixed linear models (Zimmerman and Harville, 1991; Gilmour et al., 1997; Cullis et al., 1998, Casanoves et al., $2005 \mathrm{~b}$ ), where it is not only possible to consider the correlation structure among yield data obtained from different plots but also to model residual variance heterogeneity among the trials conducted in different environments. Although the spatial modeling through geo-statistical models could potentially yield more power under certain circumstances (Casanoves et al., 2005b), more traditional approaches, such as the explicit use of block effects in the model, are simpler to interpret and may be more appealing to practitioners.

Another problem not normally addressed in classical analyses is the fact that in different environments the residual variability could be different. If this difference is not considered in modeling METs, standard errors could be underestimated for certain comparisons and overestimated for others.

The objective of this study was to see how frequent the problem of heterogeneous variances across environments appears in Peanut Breeding Program METs, and evaluate the effect of diverse spatial modeling strategies on the comparison of genotype means by location since in the presence of genotype $\times$ location interaction, environment specific inference is more informative. The following models were simultaneously adjusted for 18 METs from a plant breeding program with a RCB design in each environment: 1) classic analysis of variance model with fixed block effects (FB); 2) classic analysis of variance model with random block effects (RB); 3) classic analysis of variance model with fixed block effects adjusted with heterogeneous residual variances 
by location $(\mathrm{FBH}) ; 4)$ classic analysis of variance model with random block effects adjusted with heterogeneous residual variances by location (RBH); 5) a nearest-neighbor method as reference (PAP; Papadakis, 1937). Heterogeneous residual variances by location allow the consideration of possible differences in precision of MET conducted in different environments. The adjustments of genotype means and the statistical comparison among genotypes within each trial were used to compare the behavior of the different models.

\section{MATERIALS AND METHODS}

\section{Database}

Data used came from nine years (1984/85 to 1992/93) of METs conducted for two types of experimental peanut (Arachis hypogaea L.) genotypes in the Peanut Breeding Program at Manfredi, Instituto Nacional de Tecnología Agropecuaria (PBP-INTA), Argentina. METs for Type 1 genotypes correspond to trials involving short-cycle genotypes; METs for Type 2 genotypes, to trials where long-cycle genotypes were compared. A total of 18 METs were used in this study. These involved genotypes representing the diversity of the germplasm evaluated in early stages of the PBP-INTA. In each year, the METs were conducted at three locations in the agricultural area of the Province of Córdoba (Argentina): Manfredi (Lat. S $31^{\circ} 41^{\prime}$, Long. W 6326'); General Cabrera (Lat. S $32^{\circ} 49^{\prime}$, Long. W 635'); and Río Tercero (Lat. S $32^{\circ} 10^{\prime}$, Long. W $64^{\circ} 7^{\prime}$ ), with the exception of the 1991/92 and 1992/93 years, when Río Tercero did not participate. The climate and soil characteristics of the three locations are similar (Casanoves et al., 2005a), and the main difference among these locations was in rainfall. At each location, we evaluated an average of 15 genotypes per year in the short-cycle trials $(\min =11$ and $\max =17$ genotypes) and 14 genotypes per year in the long-cycle trials $(\min =13$ and $\max =17$ genotypes). The group of genotypes which was evaluated each year was the same for each location. At each of the three locations, both short-cycle and long-cycle genotypes trials were conducted following a RCB design with four repetitions. The plots consisted of two 10-meter-long furrows 70 centimeters apart. Recommended seeding rates ( 15 seeds $/ \mathbf{m}^{2}$ ) and cultural practices were used in all of the METs. Each plot was harvested manually after eliminating the border areas. The analyzed yield values were reported as kilograms of peanuts per plot on a standard moisture content basis $(80 \mathrm{~g} / \mathrm{kg})$.

\section{Analysis Procedures}

The grain yield data obtained each year for each MET were analyzed by using the procedures detailed below. The first two methods 
were based on analysis of variance for a randomized complete block design using the following model:

$$
\mathrm{y}_{i j k}=\mu+\mathrm{L}_{j}+\mathrm{B}(\mathrm{L})_{k(j)}+\mathrm{G}_{i}+\mathrm{GL}_{(i j)}+\varepsilon_{i j k}
$$

where $\mathrm{y}_{i j k}$ is the yield of genotype $\mathbf{i}$, in location $\mathbf{j}$, block $\mathrm{k}$; $\boldsymbol{\mu}$ is the overall mean; $\mathrm{L}_{j}$ is the effect of location $j$ with $j=1, \ldots, \mathrm{s} ; \mathrm{B}(\mathrm{L})_{k(j)}$ is the effect of block $k$ within location $j$ with $k=1, \ldots, \mathrm{n} ; \mathrm{G}_{i}$ is the effect of genotype $i$ with $i=1, \ldots, \mathrm{g} ; \mathrm{GL}_{(i j)}$ is the effect of the interaction of genotype $i$ with location $j$, and $\varepsilon_{i j k}$ is the error term associated with observation $\mathrm{y}_{i j k}$. Except for $\varepsilon_{i j k}$ and the block effects, all of the model factors were considered as fixed effects with the objective of restricting the comparison of modeling procedures to the plot structure and comparing the approximations obtained under mixed models with those of other analysis techniques used to control spatial variability. The block effects were considered fixed in model 1 (FB) and random in the second model (RB). The $\varepsilon_{i \mathrm{ik}}$ were assumed to be independent with constant variance $\sigma^{2}$ in these first two models, i.e., supposedly local spatial variation does not exist, but homogeneous residual variance does exist between locations. Two other procedures denoted as the FBH model and the RBH model were also based on equation [1] but considered the possibility that heterogeneous residual variance might be heterogeneous across locations. All models were adjusted by using Proc Mixed SAS Version 8.2 (SAS Institute, 2001) (Table 1).

Grain yield means were also adjusted with the original procedure known as the nearest-neighbor adjustment of Papadakis (1937), which uses the residues of adjacent plots to correct the genotype means for spatial variability. In order to implement the nearest-neighbor adjustment, we used the following steps, detailed in Stroup et al. (1994): 1) obtain the adjacent plot residues for a model without block effects, that is $\varepsilon_{k m}=y_{k m}-\bar{y}_{k m}$, where $e_{k m}$ is the residue in latitude $k$ th and longitude $m$ th, $y_{k m}$ and $\bar{y}_{k m}$ are the observed value and the mean value of genotype in plot $k m ; 2$ ) calculate the adjustment covariate in the east-west $(\mathrm{EW})$ direction (right to left on the field map, independent of the real orientation) from the residues obtained in step one such as $\mathrm{EO}_{k m}=$ $1 / 2\left(e_{k, m-1}+e_{k, m+1}\right)$; when the plot is the border of the block, the covariate is calculated with only the residue from the adjacent plot; 3 ) calculate the adjustment covariate in the north-south (NS) direction (from the top to the bottom of the field map, independently of the real orientation) similar to the calculation in step two, i.e., $\mathrm{NS}_{k m}=1 / 2\left(e_{k-1, m}+e_{k+1, m}\right)$; and 4) fit all three analysis of covariance models, one using the EW covariates, another the NS covariate and the third using both covariates (EW-NS). The best fit was selected from these three models to carry out 
TABLE 1.-Summarized syntax for the Proc Mixed SAS (Version 8.2) commands to fit the four models for MET.

\begin{tabular}{|c|c|}
\hline Model $^{1}$ & Syntax \\
\hline FB & $\begin{array}{l}\text { class block genotype location; model yield = genotype location } \\
\text { genotype*location block (location); }\end{array}$ \\
\hline $\mathrm{RB}$ & $\begin{array}{l}\text { class block genotype location; model yield = genotype location } \\
\text { genotype*location; random block (location); }\end{array}$ \\
\hline $\mathrm{FBH}$ & $\begin{array}{l}\text { class block genotype location; model yield = genotype location } \\
\text { genotype*location block (location); repeated/group = location; }\end{array}$ \\
\hline $\mathrm{RBH}$ & $\begin{array}{l}\text { class block genotype location; model yield = genotype location } \\
\text { genotype*location; random block (location); repeated/group = location; }\end{array}$ \\
\hline
\end{tabular}

${ }^{1} \mathrm{FB}$, fixed block effects; RB, random block effects; FBH, fixed block effects with heterogeneous residual variances; $\mathrm{RBH}$, random block effects with heterogeneous residual variances.

the iterative procedure proposed by Wilkinson et al. (1983), where the first iteration is the original procedure from Papadakis (1937) and in the rest, the plot residues are calculated by using the genotype means adjusted in the previous iteration. The procedure was repeated until the differences between the genotype means in two successive iterations were negligible. In this study, iterations were stopped when the estimation from one step was not different from that of the previous step by two decimal places (original precision of the data). This procedure was denoted as the PAP Model.

The models associated with each procedure were evaluated with Akaike's (AIC) and Schwarz's (BIC) criteria (SAS Institute, 2001), calculated as follows:

$$
\begin{gathered}
A I C=-2 L+2 d \\
B I C=-2 L+d \ln n
\end{gathered}
$$

where $L$ is the restricted maximum likelihood value, $d=q+p$ is the model dimension, $q$ is the number of estimated covariance parameters, and $p$ is the rank of the design matrix $\mathrm{X}$. The maximum likelihood estimation method was used. The best model is that with the lowest value of the AIC or BIC. Variance component estimates were calculated with the restricted maximum likelihood method (REML), and tests were carried out with the degrees of freedom adjustment proposed by Kenward and Roger (1997). As an indicator of the power of each procedure, the F statistic value was used to test the hypothesis of no genotype effects at each location of the METs. Pearson's correlation coefficients between the adjusted least square means for each genotype in each of the METs were calculated. The estimators for the covariance parameters associated with each model were also obtained to facilitate the comparison of procedures. 


\section{RESULTS AND DISCUSSION}

In all of the MET evaluated, the genotype $\times$ location interaction was significant $(\mathrm{p}<0.0001)$. In the PBP-INTA, the genotype $\times$ environment interaction within the same agricultural year was, in general, random by nature (Casanoves et al., 2005a). However, the genotypes were compared within each location not only because of this interaction but also because plot spatial correlation models may differ among locations.

When the block effect within the location was considered, it was always significant $(\mathrm{p}<0.05)$. Tables 2 and 3 present the AIC and BIC values associated with each model. According to BIC, the RB model was superior to the FB model in all cases. However, the AIC values suggested the opposite. This occurs because the plot correlation structure is modeled with one additional parameter in the RCB design with random block effects, whereas the model with fixed block effects uses nine parameters for the same objective. BIC penalizes over-parameterization more than AIC. The inference space is larger for the models with random block effects than for models with fixed block ef-

TABLE 2.-Akaike (AIC) criterion values obtained from fitting five models which incorporate spatial correlations for 18 METs.

\begin{tabular}{|c|c|c|c|c|c|c|}
\hline \multirow[b]{2}{*}{$\mathrm{Cycle}^{2}$} & \multicolumn{6}{|c|}{ Models $^{1}$} \\
\hline & Year & FB & $\mathrm{RB}$ & $\mathrm{FBH}$ & $\mathrm{RBH}$ & PAP \\
\hline 1 & $1984 / 85$ & 26.6 & 38.6 & 20.4 & 32.7 & 223.4 \\
\hline 1 & $1985 / 86$ & 60.1 & 75.1 & 61.9 & 77.4 & 154.1 \\
\hline 1 & 1986/87 & 69.4 & 84.8 & 68.8 & 83.7 & 60.9 \\
\hline 1 & $1987 / 88$ & 51.6 & 68.4 & 42.1 & 59.8 & 282.6 \\
\hline 1 & $1988 / 89$ & 53.7 & 67.7 & 22.1 & 37.6 & 259.0 \\
\hline 1 & $1989 / 90$ & 185.4 & 200.6 & 189.0 & 204.2 & 162.4 \\
\hline 1 & $1990 / 91$ & 73.5 & 79.3 & 73.6 & 79.9 & 164.1 \\
\hline 1 & $1991 / 92$ & 22.1 & 29.0 & 18.2 & 26.1 & 104.0 \\
\hline 1 & $1992 / 93$ & 18.7 & 23.1 & 17.9 & 22.8 & 219.3 \\
\hline 2 & $1984 / 85$ & 120.1 & 150.8 & 103.9 & 135.8 & 339.7 \\
\hline 2 & $1985 / 86$ & 184.6 & 185.3 & 141.5 & 140.7 & 437.0 \\
\hline 2 & $1986 / 87$ & 178.2 & 197.4 & 131.9 & 153.9 & 187.4 \\
\hline 2 & $1987 / 88$ & 67.6 & 76.2 & 68.1 & 76.5 & 262.5 \\
\hline 2 & $1988 / 89$ & 83.3 & 91.4 & 67.1 & 77.8 & 221.2 \\
\hline 2 & $1989 / 90$ & 116.1 & 121.8 & 107.7 & 114.3 & 295.4 \\
\hline 2 & $1990 / 91$ & 135.4 & 138.5 & 125.4 & 129.4 & 284.1 \\
\hline 2 & $1991 / 92$ & 41.0 & 54.5 & 34.5 & 48.2 & 189.6 \\
\hline 2 & $1992 / 93$ & 79.4 & 89.7 & 81.4 & 91.7 & 181.6 \\
\hline
\end{tabular}

${ }^{1}$ FB, fixed block effects; RB, random block effects; FBH, fixed block effects with heterogeneous residual variances; $\mathrm{RBH}$, random block effects with heterogeneous residual variances; PAP, Papadakis method.

${ }^{2}$ Short cycle genotypes, 1 ; long cycle genotypes, 2. 
TABLE 3.-Schwarz (BIC) criterion values obtained from fitting five models which incorporate spatial correlations for 18 METs.

\begin{tabular}{|c|c|c|c|c|c|c|}
\hline \multirow[b]{2}{*}{$\mathrm{Cycle}^{2}$} & \multirow[b]{2}{*}{ Year } & \multicolumn{5}{|c|}{ Models ${ }^{1}$} \\
\hline & & FB & $\mathrm{RB}$ & FBH & $\mathrm{RBH}$ & PAP \\
\hline 1 & $1984 / 85$ & 202.2 & 61.4 & 202.4 & 56.5 & 373.4 \\
\hline 1 & $1985 / 86$ & 196.7 & 93.5 & 204.5 & 96.8 & 267.0 \\
\hline 1 & $1986 / 87$ & 258.3 & 109.0 & 264.2 & 108.9 & 227.0 \\
\hline 1 & $1987 / 88$ & 254.0 & 94.1 & 251.1 & 86.4 & 458.5 \\
\hline 1 & $1988 / 89$ & 242.7 & 92.0 & 217.6 & 62.8 & 425.1 \\
\hline 1 & $1989 / 90$ & 374.4 & 224.8 & 384.5 & 229.4 & 328.5 \\
\hline 1 & $1990 / 91$ & 249.1 & 102.1 & 255.6 & 103.7 & 317.4 \\
\hline 1 & $1991 / 92$ & 93.9 & 30.9 & 92.5 & 28.1 & 163.5 \\
\hline 1 & $1992 / 93$ & 121.8 & 25.7 & 123.9 & 25.4 & 311.3 \\
\hline 2 & $1984 / 85$ & 269.5 & 170.6 & 259.4 & 156.7 & 449.5 \\
\hline 2 & $1985 / 86$ & 347.0 & 206.6 & 310.2 & 163.0 & 568.2 \\
\hline 2 & $1986 / 87$ & 367.2 & 221.6 & 327.4 & 179.1 & 340.5 \\
\hline 2 & $1987 / 88$ & 243.2 & 99.0 & 250.1 & 100.3 & 296.7 \\
\hline 2 & $1988 / 89$ & 285.7 & 117.1 & 276.1 & 104.4 & 400.3 \\
\hline 2 & $1989 / 90$ & 291.7 & 144.6 & 289.7 & 138.0 & 448.7 \\
\hline 2 & $1990 / 91$ & 284.8 & 158.4 & 281.0 & 150.2 & 376.2 \\
\hline 2 & $1991 / 92$ & 128.2 & 56.7 & 124.4 & 50.5 & 263.6 \\
\hline 2 & $1992 / 93$ & 166.7 & 92.0 & 171.3 & 94.0 & 255.6 \\
\hline
\end{tabular}

${ }^{1}$ FB, fixed block effects; RB, random block effects; FBH, fixed block effects with heterogeneous residual variances; $\mathrm{RBH}$, random block effects with heterogeneous residual variances; PAP, Papadakis method.

${ }^{2}$ Short cycle genotypes, 1 ; long cycle genotypes, 2 .

fects, since it is not restricted to the group of plots actually used in the experiment. Other measures, such as mean differences and their standard error are the same in balanced design with random or fixed block effects. The traditional methods based on blocking plots, even when the block effects are treated as fixed or random, can be conceptualized as special spatial modeling cases that produce valid genotype mean estimations when the blocking assumptions are consistent with this variation. Since the block effects are totally or partially balanced with respect to the genotype effects, the genotype mean adjustments by spatial correlation, when blocking is considered, will be smaller than the adjustments corresponding to situations where blocking is not considered. By fitting models with blocks and heterogeneous residual variance between environments, both the AIC and BIC values were reduced in the majority of the METs (Tables 2 and 3). In 11 of the $18 \mathrm{METs}(62 \%)$, the difference between the residual variances was important with a ratio between the highest and the lowest residual variances greater than two (Tables 4 and 5). The differences in 
TABLE 4.-Variance component estimates for five models incorporating spatial correlation for METs involving short-cycle genotypes at the Peanut Breeding Program - Instituto Nacional de Tecnologia Agropecuaria.

\begin{tabular}{|c|c|c|c|c|c|c|}
\hline \multirow{4}{*}{$\frac{\text { Year }}{1984 / 85}$} & \multicolumn{6}{|c|}{ Models $^{1}$} \\
\hline & \multirow{3}{*}{$\begin{array}{c}\mathrm{FB} \\
\sigma^{2}=0.052\end{array}$} & \multirow{3}{*}{$\begin{array}{c}\mathrm{RB} \\
\sigma_{\mathrm{B}}^{2}=0.009 \\
\sigma^{2}=0.052\end{array}$} & \multirow{3}{*}{$\begin{array}{c}\mathrm{FBH} \\
\sigma_{\mathrm{GC}}^{2}=0.056 \\
\sigma_{\mathrm{M}}^{2}=0.030 \\
\sigma_{\mathrm{R}}^{2}=0.070\end{array}$} & \multicolumn{2}{|c|}{$\mathrm{RBH}$} & \multirow{3}{*}{$\begin{array}{c}\text { PAP } \\
\sigma^{2}=0.120\end{array}$} \\
\hline & & & & $\sigma_{\mathrm{B}}^{2}=0.008$ & $\sigma_{\mathrm{GC}}^{2}=0.058$ & \\
\hline & & & & $\sigma_{\mathrm{M}}^{2}=0.030$ & $\sigma_{\mathrm{R}}^{2}=0.069$ & \\
\hline $1985 / 86$ & $\sigma^{2}=0.062$ & $\begin{array}{l}\sigma_{\mathrm{B}}^{2}=0.021 \\
\sigma^{2}=0.068\end{array}$ & $\begin{array}{l}\sigma_{\mathrm{GC}}^{2}=0.058 \\
\sigma_{\mathrm{M}}^{2}=0.061 \\
\sigma_{\mathrm{R}}^{2}=0.085\end{array}$ & $\begin{array}{l}\sigma_{\mathrm{B}}^{2}=0.022 \\
\sigma_{\mathrm{M}}^{2}=0.060\end{array}$ & $\begin{array}{l}\sigma_{\mathrm{GC}}^{2}=0.059 \\
\sigma_{\mathrm{R}}^{2}=0.083\end{array}$ & $\sigma^{2}=0.101$ \\
\hline $1986 / 87$ & $\sigma^{2}=0.065$ & $\begin{array}{l}\sigma_{\mathrm{B}}^{2}=0.016 \\
\sigma^{2}=0.065\end{array}$ & $\begin{array}{l}\sigma_{\mathrm{GC}}^{2}=0.052 \\
\sigma_{\mathrm{M}}^{2}=0.086 \\
\sigma_{\mathrm{R}}^{2}=0.057\end{array}$ & $\begin{array}{l}\sigma_{\mathrm{B}}^{2}=0.013 \\
\sigma_{\mathrm{M}}^{2}=0.089\end{array}$ & $\begin{array}{l}\sigma_{\mathrm{GC}}^{2}=0.052 \\
\sigma_{\mathrm{R}}^{2}=0.056\end{array}$ & $\sigma^{2}=0.047$ \\
\hline $1987 / 88$ & $\sigma^{2}=0.059$ & $\begin{array}{l}\sigma_{\mathrm{B}}^{2}=0.015 \\
\sigma^{2}=0.058\end{array}$ & $\begin{array}{l}\sigma_{\mathrm{GC}}^{2}=0.058 \\
\sigma_{\mathrm{M}}^{2}=0.083 \\
\sigma_{\mathrm{R}}^{2}=0.033\end{array}$ & $\begin{array}{l}\sigma_{\mathrm{B}}^{2}=0.015 \\
\sigma_{\mathrm{M}}^{2}=0.082\end{array}$ & $\begin{array}{l}\sigma_{\mathrm{GC}}^{2}=0.059 \\
\sigma_{\mathrm{R}}^{2}=0.033\end{array}$ & $\sigma^{2}=0.139$ \\
\hline $1988 / 89$ & $\sigma^{2}=0.060$ & $\begin{array}{l}\sigma_{\mathrm{B}}^{2}=0.012 \\
\sigma^{2}=0.060\end{array}$ & $\begin{array}{l}\sigma_{\mathrm{GC}}^{2}=0.077 \\
\sigma_{\mathrm{M}}^{2}=0.083 \\
\sigma_{\mathrm{R}}^{2}=0.019\end{array}$ & $\begin{array}{l}\sigma_{\mathrm{B}}^{2}=0.010 \\
\sigma_{\mathrm{M}}^{2}=0.083\end{array}$ & $\begin{array}{l}\sigma_{\mathrm{GC}}^{2}=0.079 \\
\sigma_{\mathrm{R}}^{2}=0.019\end{array}$ & $\sigma^{2}=0.133$ \\
\hline $1989 / 90$ & $\sigma^{2}=0.119$ & $\begin{array}{l}\sigma_{\mathrm{B}}^{2}=0.028 \\
\sigma^{2}=0.119\end{array}$ & $\begin{array}{l}\sigma_{\mathrm{GC}}^{2}=0.129 \\
\sigma_{\mathrm{M}}^{2}=0.110 \\
\sigma_{\mathrm{R}}^{2}=0.119\end{array}$ & $\begin{array}{l}\sigma_{\mathrm{B}}^{2}=0.028 \\
\sigma_{\mathrm{M}}^{2}=0.110\end{array}$ & $\begin{array}{l}\sigma_{\mathrm{GC}}^{2}=0.130 \\
\sigma_{\mathrm{K}}^{2}=0.118\end{array}$ & $\sigma^{2}=0.080$ \\
\hline $1990 / 91$ & $\sigma^{2}=0.068$ & $\begin{array}{l}\sigma_{\mathrm{B}}^{2}=0.005 \\
\sigma^{2}=0.068\end{array}$ & $\begin{array}{l}\sigma_{G C}^{2}=0.088 \\
\sigma_{M}^{2}=0.063 \\
\sigma_{\mathrm{R}}^{2}=0.053\end{array}$ & $\begin{array}{l}\sigma_{\mathrm{B}}^{2}=0.005 \\
\sigma_{\mathrm{M}}^{2}=0.063\end{array}$ & $\begin{array}{l}\sigma_{\mathrm{GC}}^{2}=0.086 \\
\sigma_{\mathrm{R}}^{2}=0.054\end{array}$ & $\sigma^{2}=0.085$ \\
\hline $1991 / 92$ & $\sigma^{2}=0.057$ & $\begin{array}{l}\sigma_{\mathrm{B}}^{2}=0.009 \\
\sigma^{2}=0.057\end{array}$ & $\begin{array}{l}\sigma_{\mathrm{GC}}^{2}=0.036 \\
\sigma_{\mathrm{M}}^{2}=0.077\end{array}$ & $\begin{array}{l}\sigma_{\mathrm{B}}^{2}=0.011 \\
\sigma_{\mathrm{M}}^{2}=0.076\end{array}$ & $\sigma_{\mathrm{GC}}^{2}=0.037$ & $\sigma^{2}=0.111$ \\
\hline $1992 / 93$ & $\sigma^{2}=0.053$ & $\begin{array}{l}\sigma_{\mathrm{B}}^{2}=0.004 \\
\sigma^{2}=0.053\end{array}$ & $\begin{array}{l}\sigma_{\mathrm{GC}}^{2}=0.064 \\
\sigma_{\mathrm{M}}^{2}=0.042\end{array}$ & $\begin{array}{l}\sigma_{\mathrm{B}}^{2}=0.005 \\
\sigma_{\mathrm{M}}^{2}=0.042\end{array}$ & $\sigma_{\mathrm{GC}}^{2}=0.063$ & $\sigma^{2}=0.210$ \\
\hline
\end{tabular}

${ }^{1} \mathrm{FB}$, fixed block effects; RB, random block effects; FBH, fixed block effects with heterogeneous residual variances; $\mathrm{RBH}$, random block effects with heterogeneous residual variances; PAP, Papadakis method; $\sigma_{\mathrm{B}}^{2}$, block variance; $\sigma_{\mathrm{M}}^{2}$, residual variance for Manfredi location; $\sigma_{\mathrm{GC}}^{2}$, residual variance for General Cabrera location; $\sigma_{\mathrm{R}}^{2}$, residual variance for Río Tercero location

percentages between the highest and the lowest residual variance for location vary between $36 \%$ (Table $4,1989 / 90$ year) and $623 \%$ (Table 5 , 1986/87 year). The FB model, traditionally used for PBP-INTA MET analysis, was not the best model for fitting the data in any of the 18 MET. The largest differences were observed in the METs with long- 
TABLE 5.-Variance component estimates for five models incorporating spatial correlation for METs involving long-cycle genotypes at the Peanut Breeding Program - Instituto Nacional de Tecnología Agropecuaria.

\begin{tabular}{|c|c|c|c|c|c|c|}
\hline \multirow{3}{*}{$\frac{\text { Year }}{1984 / 85}$} & \multicolumn{6}{|c|}{ Models $^{1}$} \\
\hline & \multirow{2}{*}{$\begin{array}{c}\mathrm{FB} \\
\sigma^{2}=0.106\end{array}$} & \multirow{2}{*}{$\begin{array}{c}\mathrm{RB} \\
\sigma_{\mathrm{B}}^{2}=0.121 \\
\sigma^{2}=0.106\end{array}$} & \multirow{2}{*}{$\begin{array}{c}\mathrm{FBH} \\
\sigma_{\mathrm{GC}}^{2}=0.063 \\
\sigma_{\mathrm{M}}^{2}=0.158 \\
\sigma_{\mathrm{R}}^{2}=0.097\end{array}$} & \multicolumn{2}{|c|}{$\mathrm{RBH}$} & \multirow{2}{*}{$\begin{array}{c}\text { PAP } \\
\sigma^{2}=0.326\end{array}$} \\
\hline & & & & $\begin{array}{l}\sigma_{\mathrm{B}}^{2}=0.116 \\
\sigma_{\mathrm{M}}^{2}=0.160\end{array}$ & $\begin{array}{l}\sigma_{\mathrm{GC}}^{2}=0.063 \\
\sigma_{\mathrm{K}}^{2}=0.096\end{array}$ & \\
\hline $1985 / 86$ & $\sigma^{2}=0.137$ & $\begin{array}{l}\sigma_{\mathrm{B}}^{2}=0.004 \\
\sigma^{2}=0.137\end{array}$ & $\begin{array}{l}\sigma_{\mathrm{GC}}^{2}=0.287 \\
\sigma_{\mathrm{M}}^{2}=0.050 \\
\sigma_{\mathrm{R}}^{2}=0.073\end{array}$ & $\begin{array}{l}\sigma_{\mathrm{B}}^{2}=0.001 \\
\sigma_{\mathrm{M}}^{2}=0.050\end{array}$ & $\begin{array}{l}\sigma_{\mathrm{GC}}^{2}=0.297 \\
\sigma_{\mathrm{R}}^{2}=0.073\end{array}$ & $\sigma^{2}=0.479$ \\
\hline $1986 / 87$ & $\sigma^{2}=0.114$ & $\begin{array}{l}\sigma_{\mathrm{B}}^{2}=0.041 \\
\sigma^{2}=0.114\end{array}$ & $\begin{array}{l}\sigma_{\mathrm{GC}}^{2}=0.212 \\
\sigma_{\mathrm{M}}^{2}=0.094 \\
\sigma_{\mathrm{R}}^{2}=0.034\end{array}$ & $\begin{array}{l}\sigma_{\mathrm{B}}^{2}=0.039 \\
\sigma_{\mathrm{M}}^{2}=0.095\end{array}$ & $\begin{array}{l}\sigma_{\mathrm{GC}}^{2}=0.212 \\
\sigma_{\mathrm{K}}^{2}=0.035\end{array}$ & $\sigma^{2}=0.095$ \\
\hline $1987 / 88$ & $\sigma^{2}=0.066$ & $\begin{array}{l}\sigma_{\mathrm{B}}^{2}=0.008 \\
\sigma^{2}=0.066\end{array}$ & $\begin{array}{l}\sigma_{\mathrm{GC}}^{2}=0.085 \\
\sigma_{\mathrm{M}}^{2}=0.056 \\
\sigma_{\mathrm{R}}^{2}=0.057\end{array}$ & $\begin{array}{l}\sigma_{\mathrm{B}}^{2}=0.007 \\
\sigma_{\mathrm{M}}^{2}=0.055\end{array}$ & $\begin{array}{l}\sigma_{\mathrm{GC}}^{2}=0.087 \\
\sigma_{\mathrm{R}}^{2}=0.057\end{array}$ & $\sigma^{2}=0.149$ \\
\hline $1988 / 89$ & $\sigma^{2}=0.068$ & $\begin{array}{l}\sigma_{\mathrm{B}}^{2}=0.007 \\
\sigma^{2}=0.068\end{array}$ & $\begin{array}{l}\sigma_{\mathrm{GC}}^{2}=0.107 \\
\sigma_{\mathrm{M}}^{2}=0.035 \\
\sigma_{\mathrm{R}}^{2}=0.062\end{array}$ & $\begin{array}{l}\sigma_{\mathrm{B}}^{2}=0.009 \\
\sigma_{\mathrm{M}}^{2}=0.036\end{array}$ & $\begin{array}{l}\sigma_{\mathrm{GC}}^{2}=0.105 \\
\sigma_{\mathrm{R}}^{2}=0.062\end{array}$ & $\sigma^{2}=0.102$ \\
\hline $1989 / 90$ & $\sigma^{2}=0.086$ & $\begin{array}{l}\sigma_{\mathrm{B}}^{2}=0.007 \\
\sigma^{2}=0.086\end{array}$ & $\begin{array}{l}\sigma_{\mathrm{GC}}^{2}=0.049 \\
\sigma_{\mathrm{M}}^{2}=0.088 \\
\sigma_{\mathrm{R}}^{2}=0.123\end{array}$ & $\begin{array}{l}\sigma_{\mathrm{B}}^{2}=0.007 \\
\sigma_{\mathrm{M}}^{2}=0.085\end{array}$ & $\begin{array}{l}\sigma_{\mathrm{GC}}^{2}=0.049 \\
\sigma_{\mathrm{K}}^{2}=0.124\end{array}$ & $\sigma^{2}=0.177$ \\
\hline $1990 / 91$ & $\sigma^{2}=0.107$ & $\begin{array}{l}\sigma_{\mathrm{B}}^{2}=0.006 \\
\sigma^{2}=0.107\end{array}$ & $\begin{array}{l}\sigma_{\mathrm{GC}}^{2}=0.112 \\
\sigma_{\mathrm{M}}^{2}=0.150 \\
\sigma_{\mathrm{R}}^{2}=0.053\end{array}$ & $\begin{array}{l}\sigma_{\mathrm{B}}^{2}=0.006 \\
\sigma_{\mathrm{M}}^{2}=0.152\end{array}$ & $\begin{array}{l}\sigma_{\mathrm{GC}}^{2}=0.117 \\
\sigma_{\mathrm{R}}^{2}=0.053\end{array}$ & $\sigma^{2}=0.167$ \\
\hline $1991 / 92$ & $\sigma^{2}=0.066$ & $\begin{array}{l}\sigma_{\mathrm{B}}^{2}=0.029 \\
\sigma^{2}=0.066\end{array}$ & $\begin{array}{l}\sigma_{G C}^{2}=0.041 \\
\sigma_{M}^{2}=0.092\end{array}$ & $\begin{array}{l}\sigma_{\mathrm{B}}^{2}=0.025 \\
\sigma_{\mathrm{M}}^{2}=0.094\end{array}$ & $\sigma_{\mathrm{GC}}^{2}=0.040$ & $\sigma^{2}=0.212$ \\
\hline $1992 / 93$ & $\sigma^{2}=0.096$ & $\begin{array}{l}\sigma_{\mathrm{B}}^{2}=0.025 \\
\sigma^{2}=0.096\end{array}$ & $\begin{array}{l}\sigma_{\mathrm{GC}}^{2}=0.099 \\
\sigma_{\mathrm{M}}^{2}=0.093\end{array}$ & $\begin{array}{l}\sigma_{\mathrm{B}}^{2}=0.026 \\
\sigma_{\mathrm{M}}^{2}=0.094\end{array}$ & $\sigma_{\mathrm{GC}}^{2}=0.098$ & $\sigma^{2}=0.196$ \\
\hline
\end{tabular}

${ }^{1} \mathrm{FB}$, fixed block effects; RB, random block effects; FBH, fixed block effects with heterogeneous residual variances; $\mathrm{RBH}$, random block effects with heterogeneous residual variances; PAP, Papadakis method; $\sigma_{\mathrm{B}}^{2}$, block variance; $\sigma_{\mathrm{M}}^{2}$, residual variance for Manfredi location; $\sigma_{\mathrm{GC}}^{2}$, residual variance for General Cabrera location; $\sigma_{\mathrm{R}}^{2}$, residual variance for Río Tercero location.

cycle experimental genotypes. These genotypes remained on the ground longer; thus the trials could have greater experimental error and differences between locations because of the impact of climatic factors during a longer period. With the exception of the years 1987/ 88 and 1992/93, in all of the METs for long-cycle genotypes, both fitting criteria suggested that the models for a heteroscedastic block design are more appropriate than their homogeneous residual vari- 
ance versions (Tables 2 and 3). The two years where the FBH and $\mathrm{RBH}$ models were not superior to the FB and $\mathrm{RB}$, respectively, were the only years where the differences in residual variances between locations were negligible (Tables 6 and 7). For these two years, the differences between the F statistic for the hypothesis test of no genotype effect obtained within each location were very similar for the homogeneous and heterogeneous block design models. However, in the majority of the METs for long-cycle genotypes, important F statis-

TABLE 6.-F statistics for the mean comparison by location for four models incorporating spatial correlation between plots for Peanut Breeding Program-Instituto Nacional de Tecnologia Agropecuaria METs for short-cycle genotypes.

\begin{tabular}{|c|c|c|c|c|c|c|}
\hline \multirow[b]{2}{*}{ Year } & \multirow[b]{2}{*}{ Location } & \multicolumn{5}{|c|}{ Models $^{1}$} \\
\hline & & FB & $\mathrm{RB}$ & FBH & $\mathrm{RBH}$ & Best model $^{2}$ \\
\hline \multirow[t]{3}{*}{$1984 / 85$} & General Cabrera & 11.71 & 11.71 & 10.86 & 10.57 & \multirow[t]{3}{*}{$\mathrm{RBH}$} \\
\hline & Manfredi & 8.87 & 8.87 & 15.15 & 15.30 & \\
\hline & Río Tercero & 5.12 & 5.12 & 3.83 & 3.87 & \\
\hline \multirow[t]{3}{*}{$1985 / 86$} & General Cabrera & 11.21 & 11.21 & 13.22 & 12.89 & \multirow[t]{3}{*}{$\mathrm{RB}$} \\
\hline & Manfredi & 6.28 & 6.28 & 6.96 & 7.06 & \\
\hline & Río Tercero & 4.94 & 4.94 & 3.95 & 4.02 & \\
\hline \multirow[t]{3}{*}{$1986 / 87$} & General Cabrera & 17.77 & 17.77 & 22.01 & 22.24 & \multirow[t]{3}{*}{$\mathrm{RBH}$} \\
\hline & Manfredi & 5.91 & 5.91 & 4.48 & 4.32 & \\
\hline & Río Tercero & 3.00 & 3.00 & 3.43 & 3.47 & \\
\hline \multirow[t]{3}{*}{$1987 / 88$} & General Cabrera & 13.15 & 13.15 & 13.14 & 12.93 & \multirow[t]{3}{*}{ RBH } \\
\hline & Manfredi & 4.97 & 4.97 & 13.49 & 3.53 & \\
\hline & Río Tercero & 10.09 & 10.09 & 17.53 & 17.59 & \\
\hline \multirow[t]{3}{*}{$1988 / 89$} & General Cabrera & 1.99 & 1.99 & 1.55 & 1.50 & \multirow[t]{3}{*}{$\mathrm{RBH}$} \\
\hline & Manfredi & 14.78 & 14.78 & 10.62 & 10.72 & \\
\hline & Río Tercero & 4.76 & 4.76 & 14.90 & 14.97 & \\
\hline \multirow[t]{3}{*}{$1989 / 90$} & General Cabrera & 5.38 & 5.38 & 4.98 & 4.95 & \multirow[t]{3}{*}{ RB } \\
\hline & Manfredi & 5.63 & 5.63 & 6.09 & 6.08 & \\
\hline & Río Tercero & 3.65 & 3.65 & 3.67 & 3.70 & \\
\hline \multirow[t]{3}{*}{$1990 / 91$} & General Cabrera & 2.34 & 2.34 & 1.82 & 1.84 & \multirow[t]{3}{*}{ RB } \\
\hline & Manfredi & 3.04 & 3.04 & 3.27 & 3.30 & \\
\hline & Río Tercero & 5.02 & 5.02 & 6.42 & 6.33 & \\
\hline \multirow[t]{2}{*}{ 1991/92 } & General Cabrera & 7.85 & 7.85 & 12.16 & 12.04 & \multirow[t]{2}{*}{$\mathrm{RBH}$} \\
\hline & Manfredi & 8.12 & 8.12 & 6.00 & 6.13 & \\
\hline \multirow[t]{2}{*}{ 1992/93 } & General Cabrera & 13.27 & 13.27 & 10.95 & 11.10 & \multirow[t]{2}{*}{$\mathrm{RBH}$} \\
\hline & Manfredi & 20.81 & 20.81 & 26.40 & 26.18 & \\
\hline
\end{tabular}

${ }^{1} \mathrm{FB}$, fixed block effects; RB, random block effects; FBH, fixed block effects with heterogeneous residual variances; $\mathrm{RBH}$, random block effects with heterogeneous residual variances.

${ }^{2}$ According to BIC criterion (SAS Institute, 2001). 
TABLE 7.-F statistics for the mean comparison by location for four models incorporating spatial correlation between plots for Peanut Breeding Program-Instituto Nacional de Tecnología Agropecuaria METs for long-cycle genotypes.

\begin{tabular}{|c|c|c|c|c|c|c|}
\hline \multirow[b]{2}{*}{ Year } & \multirow[b]{2}{*}{ Location } & \multicolumn{5}{|c|}{ Models of analysis ${ }^{1}$} \\
\hline & & FB & $\mathrm{RB}$ & $\mathrm{FBH}$ & $\mathrm{RBH}$ & Best model $^{2}$ \\
\hline \multirow[t]{3}{*}{$1984 / 85$} & General Cabrera & 12.64 & 12.64 & 21.21 & 21.25 & RBH \\
\hline & Manfredi & 18.40 & 18.40 & 12.32 & 12.20 & \\
\hline & Río Tercero & 4.34 & 4.34 & 4.76 & 4.77 & \\
\hline \multirow[t]{3}{*}{$1985 / 86$} & General Cabrera & 37.37 & 37.37 & 17.84 & 17.22 & $\mathrm{RBH}$ \\
\hline & Manfredi & 7.08 & 7.08 & 19.32 & 19.23 & \\
\hline & Río Tercero & 2.20 & 2.20 & 4.08 & 4.15 & \\
\hline \multirow[t]{3}{*}{$1986 / 87$} & General Cabrera & 9.88 & 9.88 & 5.30 & 5.30 & $\mathrm{RBH}$ \\
\hline & Manfredi & 15.79 & 15.79 & 19.06 & 18.90 & \\
\hline & Río Tercero & 4.79 & 4.79 & 15.59 & 15.63 & \\
\hline \multirow[t]{3}{*}{$1987 / 88$} & General Cabrera & 9.21 & 9.21 & 7.13 & 6.69 & $\mathrm{RB}$ \\
\hline & Manfredi & 9.60 & 9.60 & 11.33 & 11.40 & \\
\hline & Río Tercero & 9.98 & 9.98 & 11.58 & 11.65 & \\
\hline \multirow[t]{3}{*}{$1988 / 89$} & General Cabrera & 5.69 & 5.69 & 3.63 & 3.71 & $\mathrm{RBH}$ \\
\hline & Manfredi & 7.23 & 7.23 & 13.94 & 13.74 & \\
\hline & Río Tercero & 3.57 & 3.57 & 3.91 & 3.95 & \\
\hline \multirow[t]{3}{*}{$1989 / 90$} & General Cabrera & 4.22 & 4.22 & 7.49 & 7.40 & RBH \\
\hline & Manfredi & 11.85 & 11.85 & 11.67 & 12.00 & \\
\hline & Río Tercero & 8.67 & 8.67 & 6.10 & 6.03 & \\
\hline \multirow[t]{3}{*}{$1990 / 91$} & General Cabrera & 3.21 & 3.21 & 2.88 & 2.96 & $\mathrm{RBH}$ \\
\hline & Manfredi & 5.66 & 5.66 & 4.06 & 3.99 & \\
\hline & Río Tercero & 6.90 & 6.90 & 14.02 & 13.93 & \\
\hline \multirow[t]{2}{*}{ 1991/92 } & General Cabrera & 14.79 & 14.79 & 24.15 & 24.35 & $\mathrm{RBH}$ \\
\hline & Manfredi & 11.90 & 11.90 & 8.57 & 8.41 & \\
\hline \multirow[t]{2}{*}{ 1992/93 } & General Cabrera & 9.95 & 9.95 & 9.60 & 9.75 & $\mathrm{RB}$ \\
\hline & Manfredi & 3.96 & 3.96 & 4.11 & 4.05 & \\
\hline
\end{tabular}

1FB, fixed block effects; RB, random block effects; FBH, fixed block effects with heterogeneous residual variances; $\mathrm{RBH}$, random block effects with heterogeneous residual variances.

${ }^{2}$ According to BIC criterion (SAS Institute, 2001).

tic changes were found in at least one of the three locations involved for each of the MET (Table 7). Considering both the METs for longand short-cycle genotypes, the FBH model was more appropriate than the FB model in $78 \%$ of the METs analyzed. Something similar occurred when models RB and RBH were compared. According to AIC, the model with heterogeneous residual variance was better in $82 \%$ of the cases, whereas according to BIC the second model was superior in $72 \%$ of the cases. It is important to note that even though BIC penal- 
izes for estimating a large number of parameters, the models with heterogeneous residual variance are recommended for MET.

When a nearest neighbor adjustment method was used (Stroup et al., 1994), the adjustments directly affected the mean estimates, since this analysis is based on covariables. Table 8 lists the significance of the adjustment covariates by EW, NS and EW-NS for the same MET where the analysis of covariance with different strategies for spatial correlation modeling was used. In $40 \%$ of the METs, the lack of covariate significance in the three covariance models suggested that adjustment for spatial correlation was not needed; that is to say, NS, EW, or both were non significant (Table 8). For the rest of the MET, the model with the EW covariate was generally best; i.e., it removed the intra-block spatial correlation variable. In two years, 1986/87 and 1989/90, for the MET with short-cycle genotypes, the best model was that which considered both the EW and the NS as covariates. For these two years AIC and BIC (obtained by the PAP model according to the best covariance model) suggest that the PAP model fits better than the classic analysis of variance mod-

TABLE 8.-Covariate significances to fit spatial correlation using the Papadakis method for three covariate models: with EW as a covariate, with NS as a covariate and with both covariates.

\begin{tabular}{|c|c|c|c|c|c|c|}
\hline \multirow[b]{3}{*}{$\mathrm{MET}^{2}$} & \multicolumn{5}{|c|}{ Direction $^{1}$} & \multirow[b]{3}{*}{ Best mode } \\
\hline & \multirow[b]{2}{*}{ Year } & \multirow[b]{2}{*}{$\mathrm{EW}$} & \multirow[b]{2}{*}{ NS } & \multicolumn{2}{|c|}{ EW-NS } & \\
\hline & & & & EW & NS & \\
\hline 1 & $1984 / 85$ & 0.0368 & 0.3471 & 0.0084 & 0.0617 & EW \\
\hline 1 & $1985 / 86$ & $<0.0001$ & 0.9601 & $<0.0001$ & 0.4089 & EW \\
\hline 1 & $1986 / 87$ & $<0.0001$ & 0.0939 & $<0.0001$ & 0.0103 & EW-NS \\
\hline 1 & $1987 / 88$ & 0.0047 & 0.8188 & 0.0020 & 0.2015 & EW \\
\hline 1 & $1988 / 89$ & 0.1085 & 0.5408 & 0.1391 & 0.9753 & None \\
\hline 1 & $1989 / 90$ & $<0.0001$ & $<0.0001$ & $<0.0001$ & 0.0033 & EW-NS \\
\hline 1 & $1990 / 91$ & 0.4905 & 0.7487 & 0.4995 & 0.7693 & None \\
\hline 1 & $1991 / 92$ & 0.0803 & 0.0367 & 0.1508 & 0.0672 & NS \\
\hline 1 & $1992 / 93$ & 0.5576 & 0.8674 & 0.5521 & 0.8393 & None \\
\hline 2 & $1984 / 85$ & 0.0002 & 0.0485 & 0.0001 & 0.0300 & EW-NS \\
\hline 2 & $1985 / 86$ & 0.7984 & 0.6078 & 0.7636 & 0.5921 & None \\
\hline 2 & $1986 / 87$ & $<0.0001$ & 0.8746 & $<0.0001$ & 0.8251 & EW \\
\hline 2 & $1987 / 88$ & 0.0006 & 0.8542 & 0.0005 & 0.5528 & EW \\
\hline 2 & $1988 / 89$ & 0.1209 & 0.9580 & 0.1099 & 0.6809 & None \\
\hline 2 & $1989 / 90$ & 0.2446 & 0.1857 & 0.1342 & 0.1044 & None \\
\hline 2 & $1990 / 91$ & 0.2683 & 0.0980 & 0.1933 & 0.0740 & None \\
\hline 2 & $1991 / 92$ & 0.0020 & 0.2136 & 0.0042 & 0.6233 & $\mathrm{EW}$ \\
\hline 2 & $1992 / 93$ & 0.0416 & 0.2454 & 0.2829 & 0.2863 & EW \\
\hline
\end{tabular}

${ }^{1} \mathrm{EW}$, east-west direction; NS, north-south direction.

${ }^{2}$ Short cycle genotypes, 1 ; long cycle genotypes, 2 . 
els (with either fixed or random block effects). Also in this case the correlation between the means adjusted for nearest neighbors and for mixed spatial showed a highly significant value $(\mathrm{r}=0.99, \mathrm{P}<0.0001)$. However, in the majority of the METs, the analysis of variance models were superior to the nearest neighbor method. There are possible nonlinear spatial correlations between plots. The results suggest that the use of procedures adjusted for nearest neighbors such as the type proposed by Papadakis (1937) is limited, since on the one hand the residues from the neighboring plots do not always have a linear relationship with the yield in the study plot (a necessary assumption for the analysis of covariance); on the other hand, the resulting model is non-linear because it incorporates a product of two parameters to be estimated. Therefore, iterative processes are required in order to make combined estimations for these parameters. Furthermore, if the trial is conducted in blocks even under the covariance model, the implemented randomization process, which incorporates block effects, should be considered.

\section{CONCLUSIONS}

The model with fixed block effects, which is traditionally used for PMM-INTA MET analysis, was not the best model to fit the data in any of the 18 METs. The greatest differences were observed in the MET with long-cycle experimental genotypes.

The analysis of variance models with a block design and heteroscedastic errors between locations are more appropriate than their homogeneous residual variance versions. In balanced designs, the standard error for the mean differences is the same for models with fixed block effects as for models with random block effects; therefore, both models achieve the same mean differences. However, with the random block effects models the inference space for comparing genotype effects is larger since it is not restricted to the combined plots used in the experiment. Modeling of the local spatial tendencies using an analysis of variance including heterogeneous residual variances increased the ability to identify differences among genotypes. These results are likely to be similar in other crops, especially in METs with very diverse environments.

\section{LITERATURE CITED}

Besag, J. E., 1974. Spatial interaction and the statistical analysis of lattice systems. J. R. Stat. Soc. Series B 36:192-225.

Besag, J. E., 1977. Errors-in-variables estimation for Gaussian lattice schemes. J. R. Stat. Soc. Series B 39:73-78.

Besag, J. E. and R. A. Kempton, 1986. Statistical analysis of field experiments using neighboring plots. Biometrics 42:231-251. 
Casanoves, F., J. Baldessari and M. Balzarini, 2005a. Evaluation of multi-environmental trials of peanut (Arachis hypogaea L.) cultivars. Crop Sci. 45:18-26.

Casanoves, F., R. Macchiavelli and M. Balzarini, 2005b. Error variation in multienvironment peanut trials: Within-trial spatial correlation and between-trial heterogeneity. Crop Sci. 45: 1927-1933.

Cullis, B. R., B. J. Gogel, A. P. Verbyla and R. Thompson, 1998. Spatial analysis of multienvironment early generation trials. Biometrics 54:1-18.

Cullis, B. R. and A. C. Gleeson, 1991. Spatial analysis of field experiments-an extension to two dimensions. Biometrics 47:1449-1460.

Cullis, B. R., F. M. Thompson, J. A. Fisher, A. R. Gilmour and R. Thompson, 1996. The analysis of the NSW wheat variety database. II. Variance component estimation. Theor. Appl. Genet. 92:28-39.

Gilmour, A. R., R. Thompson, B. R. Cullis and A. P. Verbyla, 1997. Accounting for natural and extraneous variation in the analysis of field experiments. J. Agric. Biol. Env. Stat. 2:269:273.

Gleeson, A. C. and B. R. Cullis, 1987. Residual maximum likelihood (REML) estimation of a neighbor model for field experiments. Biometrics 43:277-288.

Gusmao, L., 1986. Inadequacy of blocking in cultivar yield trials. Theor. Appl. Genet. 72:98-104.

Kempton, R. A. and G. Lockwood, 1984. Inter-plot competition in variety trials of field beans (Vicia fava L.). J. Agric. Sci., Camb. 98:599-611.

Kenward, M. G. and J. H. Roger, 1997. Small sample inference for fixed effects from restricted maximum likelihood. Biometrics 53:983-997.

Mead, R., 1971. Models for interplant competition in irregularly spaced population. p. 13-22 In: Statistical Ecology. Patil, G. P., E. C. Pielou and W. E. Waters (eds.). Pennsylvania State University Press, College Town, Pa.

Mercer, W. B. and A. D. Hall, 1911. The experimental error of field trials. J. Agric. Sci., Camb. 4:107-132.

Papadakis, J. S., 1937. Méthode statistique pour des expériences sur champ. Institut d'Amélioration des Plantes à Thessaloniki.

Pearce, S. C., 1980. Randomized blocks and some alternatives: A study in tropical conditions. Trop. Agric. (Trinidad) 57:1-10.

Ripley, B. D., 1981. Spatial Statisties. Wiley, New York.

SAS Institute Inc., 2001. SAS/STAT release 8.2. SAS Inst., Cary, NC.

Smith, A. B., B. R. Cullis and R. Thompson, 2001. Analyzing variety by environment data using multiplicative mixed models and adjustments for special field trend. Biometrics 57:1138-1147.

Stroup, W. W., P. S. Baenziger and D. K. Mulitze, 1994. Removing spatial variation from wheat yield trials: A comparison of methods. Crop Sci. 34:62-66.

Wilkinson, G. N., S. R. Eckert, T. W. Hancock and O. Mayo, 1983. Nearest neighbor analysis with field experiments. J. R. Stat. Soc. Series B 45:151-178.

Zimmerman, D. L. and D. A. Harville, 1991. A random field approach to the analysis of field plot experiments and other spatial experiments. Biometrics 47:223-239. 